\title{
Fostering Multimedia Learning with Collaborative Concept Mapping: The Effect of Cognitive Aid on Performance and on Collaboration
}

\author{
Santiago Roger Acuña ${ }^{1}$, Gabriela López Aymes $^{2}$ \& Carlos Sergio López Medrano ${ }^{1}$ \\ ${ }^{1}$ School of Communication Sciences, Autonomous University of San Luis Potosí, San Luis Potosí, México \\ ${ }^{2}$ Faculty of Human Communication, Autonomous University of Morelos State, Cuernavaca, México \\ Correspondence: Santiago Roger Acuña, School of Communication Sciences, Autonomous University of San Luis \\ Potosí, San Luis Potosí, México. E-mail: santiagoacu1@gmail.com
}

Received: January 25, 2014

Accepted: May 7, 2014

Online Published: May 10, 2014

doi:10.5430/ijhe.v3n2p141

URL: http://dx.doi.org/10.5430/ijhe.v3n2p141

\begin{abstract}
This paper analyzes the use of collaborative concept maps in multimedia learning tasks. Specifically, the effect of a cognitive aid (providing students a list of main concepts to generate a concept map) on the performance of collaborative concept mapping and on the level of collaboration in this task is discussed. The study was carried out with 57 university students, grouped into 19 triads, assigned to one of two conditions: with and without the support of a list of key concepts. It was found that the first condition promoted higher quality concept maps; however, the cognitive aid did not have significant effect on the levels of collaboration perceived by the team members. In the discussion and conclusions, the implications of these results for the design and implementation of collaborative interventions based on the use of technological tools and concept mapping are pointed out.
\end{abstract}

Keywords: Collaborative learning, Concept mapping, Multimedia learning, Cognitive aid

\section{Introduction}

As is well known, concept maps are graphical tools to organize and represent knowledge in a network of hierarchically ordered concepts (Novak \& Cañas, 2006). For example, in a concept map, the most simple and reduced form would be constituted by two concepts, a link and a linking word that specifies the relation between both concepts.

In educational contexts, among other uses, concept maps can be used, for example, as an instructional strategy to foster the acquisition of knowledge from traditional printed texts and digital texts, such as hypertext and multimedia, in situations of individual and collaborative learning (Basque \& Lavoie, 2006; Chang, Sung, \& Chen, 2001; Gao, Shen, Losh, \& Turner, 2007; Hilbert \& Renkl 2008; Oliver, 2009).

Specifically, in collaborative learning, concept maps function as scaffolds that would help structure the activity, encouraging the interaction of learners and allowing the building of shared meanings starting from the information presented in a given text. In this sense, concept maps could facilitate learners: a) in activating their previous knowledge; b) at the joint building of knowledge through information exchange and negotiation of meanings (Cañas \& Novak, 2005; Stayonova \& Kommers, 2002; van Boxtel, van der Linden, \& Kanselaar, 1997, 2000; van Boxtel, van der Linden, Roelofs, \& Erkens, 2002); and c) the development of more complex metacognitive processes related to self-regulated learning and collaboration with their peers (Chularut \& DeBacker, 2003). In the particular case of collaborative learning situations with multimedia, concept mapping could also help address the requirements of nonlinear information processing presented in multiple representational formats (Amadieu \& Salmeron, in press).

However, understanding and learning with concept maps is not that easy. It is very likely that learners who are just starting in this kind of tasks have difficulty and experience a cognitive overload. For example, in recent studies Hilbert and Renkl $(2008,2009)$ identified some specific deficits in novice mappers such as a difficulty in using of strategic planning and control of tasks, in addition to inconvenience when labeling links among concepts. Also, when this activity was carried out collaboratively, it was observed that task performance may be affected by the levels and characteristics of exchanges between learners. In this regard, Carter (1998) reported that students often do not pay attention to the comments of their colleagues and therefore fail to capitalize on the various opportunities that the task provides for the construction of meanings. As a result, they usually resort to memorization and fail to generate discussions on ideas, struggling to establish the hierarchical relationships that concept mapping requires. Not surprisingly, scaffolding has been proposed to accompany the task of concept mapping, for example, to provide 
learners with key concepts and some relevant links (Chang et al., 2001), in order to materialize the advantages of concept maps. However, these aids have generally been tested in the individual concept mapping and in learning tasks with traditional explanatory texts. The limited number of studies in collaborative concept mapping, as well as the heterogeneous findings, point out the need of further research in this area.

This paper discusses the effects of a cognitive instructional support (provide students with lists of main concepts to generate a concept map) in the level of perceived collaboration by the students and in the performance achieved by the teams in a task of collaborative construction of concept maps, starting from the information presented in a multimedia on a topic of interpersonal communication. First, this article reviews the theoretical and empirical background of the study. Secondly, the methodology that was followed is described and reports the achieved results. Finally, the main empirical findings are discussed, pointing out some implications about learning and understanding, and multimedia learning from the instructional use of collaborative concept maps.

\section{Concept maps on comprehension and learning from multimedia}

In multimedia learning, learners, at least potentially, have a wide range of advantages respecting learning with traditional texts. In the first place, students can select and structure the information according to their needs and requirements, having the possibility to access information through different routes without the restrictions related to a sequential order. That is, by following a nonlineal or non sequential processing. In the second place, students combine and manipulate different external representations that this kind of resources provide, following distinct sensory modalities (multimedia integration processing). Consequently, digital multimedia texts will allow greater interaction with the information, promoting an active involvement in learning and a more flexible control of information. However, the understanding of nonlinear information in a multimedia presentation requires a number of processes related to navigation, information search and evaluation of information, and a semantic processing which aims to the construction of mental representations that integrate textual and pictorial information. These processes require high working memory capacity, so enough guidance is needed towards a clear objective to allow effective learning with multimedia (Mayer, 2001; Rouet, Levonen, \& Biardeau, 2001; Schnotz, 2002). It is therefore necessary to provide some tools and aids that permit students face these complex demands. Even more, taking into account that these demands increase when they learn in a collaborative way, since students, besides this, need to plan, organize and manage their collaborative exchange (Jonassen, Lee, Young, \& Laffey, 2005).

In this regard, Weinstein and Mayer (1986) have pointed out that concept maps would be a very appropriate type of tool for promoting comprehension and assimilation of new information. Concept maps, particularly, will ease students the organization, representation and processing the information presented in a multimedia text, since it will provide a scaffolding structure, in order to encode the new information to integrate it with their previous knowledge. Furthermore, concept maps allow the integration of both graphical and textual information that is activated and processed in two cognitive subsystems where, according to dual coding as proposed by Paivio (1986): one specializes in the representation and processing of nonverbal objects and events (for example, pictures, images), and another specializes in dealing with verbal representations (verbal words).

Amadieu and Salmeron (in press) have also mentioned that, at least theoretically, concept maps would be adjusted to the requirements of multimedia processing that suggest theoretical approaches such as the cognitive load theory (Pass, Renkl, \& Sweller, 2003; Sweller, van Merriënboer, \& Paas, 1998). From this theoretical approach, the use of concept maps would enable: a) to reduce the extraneous cognitive load, that is, one that imposes an inappropriate instructional design, independent of the content of the material and of the activities that comprehension processes require; b) to arouse a germane cognitive load, which is the one directly related to the mental activity required by construction and automation of knowledge; c) to keep a constant intrinsic cognitive load, related to the number of information elements and the level of element interactivity inherent in the task. That is, concept mapping would generate a reduction in extraneous cognitive load, allowing learners to use the remaining cognitive resources in the more sophisticated mental processes required for multimedia learning (Amadieu \& Salmeron, in press).

Regarding cognitive processing, it has been pointed out that when students construct a conceptual map, while reading a multimedia text, for example, they need to use and integrate "bottom-up" processes, along with "top-down" processes. For example, it is required -once the meaning of words and propositions have been grasped-, to identify the main idea of the text, from which links to other propositions are made, organizing them hierarchically to build a global idea of the text. At the same time, the construction of a concept map requires to activate prior knowledge schemes and establish new inferential links that go beyond what the text says. Thus, in the task of mapping the learner reviews the relationships between concepts, while recalling and organizing the information presented in the text, combining it with prior knowledge (Liu, Chen, \& Chang, 2010). 
Following Hilbert and Renkl (2008), concept maps, as a strategy for comprehension and learning, would cover four key functions: a) an elaboration function, that would allow previously acquired knowledge to relate with the new information to determine the main ideas and their relationships with other ideas; b) a reduction function, that would identify and retain the central ideas that form a global scheme; c) a coherence function that would favor the construction of a coherent structure of the information presented in the multimedia, while it would be useful to identify the ruptures in textual coherence, and, finally, closely related to the above; d) a metacognitive function that would favor the detection and repair of bias and gaps that may appear in the process of comprehension.

However, given the demands posed by the task of conceptual mapping, some researchers have proposed and tested different types of aid that would foster these functions adequately. For example, functions such as reduction and elaboration could be supported if students are provided with lists of main concepts and/or relationships to generate a concept map, incomplete concept maps with concepts and links to label (Chang et al., 2001; Chang, Sung, \& Chen, 2002) or examples of concept maps previously developed by experts in the field of knowledge that is intended to be learnt (Chang et al., 2002; Hauser, Nückles, \& Renkl, 2006; Hilbert, Nückles, \& Matzel, 2008), while functions such as coherence and metacognition could be promoted through supports such as involving students in tasks of correcting expert concept maps that present some conceptual nodes and incorrect links, as proposed by Chang et al. (2002).

Although the effectiveness of these scaffolds has been proven, studies such as Hauser et al. (2006) have shown that some of these aids, such as providing a list of principal concepts and relationships between them, can reduce the attention on specific aspects of the learning process, in an inappropriate manner, without generating significant benefits for learning.

Anyway, much of the research on concept maps as a strategy for understanding and learning with different kinds of tools has turned its analysis to individuals undertaking tasks, so it is necessary to clarify the influence of conceptual mapping tasks and their support in learning when working collaboratively (Nesbitt \& Adesope, 2006).

\section{Learning with Collaborative Concept Maps}

Collaborative learning requires the structuring of the collaborative process in order to favor the appearance of productive interactions. For this, apprentices should assume a high level of active involvement and take responsibility of their own learning, and also their peer's (Dillenbourg, 1999). Therefore, collaborative learning is a socially mediated activity in which knowledge is built in a combined, located and distributed way. This occurs due to the dynamic interaction established among apprentices, the sociocultural environment in which the activity is developed and the cultural instruments used in such activity (Salomon, 1995). In a collaborative task a series of exchanges are fostered, where the roles played in this joint activity are internalized and will favor the internalization of new functions or the restructuring of existing ones (Vygotsky, 1978; Wood, Bruner, \& Ross, 1976). In this sense, the collaborative concept mapping functions as scaffolds that would facilitate the interaction of learners and allow the construction of shared meaning from information presented in a particular educational material.

van Boxtel et al. (2002) have pointed out that the use of collaborative concept maps would induce students to engage in two kinds of actions that are central to understanding and learning: a) elaborative actions, and b) negotiation of meanings actions. First, the collaborative concept mapping offers diverse opportunities to generate interactions that promote the development of knowledge. For example, it would increase the amount of shared information , presenting it visually, in a concrete and concise manner. The collaborative construction of the concept map induces students to identify the concepts presented in the text, exchange the meanings they attach to these concepts and explicit the relationships between these ideas. Secondly, following van Boxtel et al. (2002), collaborative concept mapping would raise the right conditions to negotiate knowledge actions where students are not only forced to reflect and develop their own knowledgebut also need to consider, integrate and develop their teammates'.

It is not strange, then, that the collaborative use of concept maps in assorted learning settings has been generalized increasingly, specially for learning diverse scientific concepts from different kinds of texts (Haugwitz, Nesbit, \& Sandmann, 2010; Kinchin, De-Leij, \& Hay, 2005; Kwon \& Cifuentes, 2009; van Boxtel et al., 2000).

While research on collaborative concept mapping has found results that confirm the possibilities and advantages of concept maps - not only regarding to another kind of collaborative learning tasks (preparing abstracts, writing essays, making a poster) but also to the individual construction of concept maps - some studies have reported conflicting results concerning the positive effects of collaborative maps in learning (for a literature review see Basque \& Lavoie, 2006; Gao et al., 2007; Nesbitt \& Adesope, 2006). Therefore, one might think that the use of collaborative concept maps by itself does not guarantee that high levels of learning are fostered. As Nesbitt \& Adesope (2006) mention, the potential advantages of collaborative concept maps are closely related both to the type and quality of interactions and 
the collaborative structure in which the use of collaborative concept mapping is delimited, such as the characteristics of the task and the system supports it provides.

Certainly, on one hand, several studies have found that some groups' performance in collaborative concept mapping tasks is closely related to the levels and characteristics of the exchanges in these groups. For example, Chiu, Huang, and Chang (2000) found out that in collaborative online environments to a greater level of complex interaction - such as providing explanations and exchanging ideas- a higher performance in collaborative work with concept maps was achieved at Information Technology topics. Furthermore, van Boxtel et al. $(1997 ; 2000)$ found results that correlate the frequency of elaborative episodes -in which students engage in discussions where they have to express their views over the concept of electricity- showing a higher learning level of this concept.

Moreover, empirical research is still nascent regarding the characteristics of the collaborative context and the aids provided in collaborative concept mapping tasks. Some studies have inquired about the configuration of working groups. For example, Kinchin et al. (2005) obtained results showing that heterogeneous collaborative groups allow students to provide different points of view, benefiting a more effective work in collaborative concept mapping. Also, Haugwitz et al. (2010) found that students with above average cognitive abilities achieved higher performance in an abstracting collaborative task using concept maps if they work in heterogeneous groups where they interact with students with low level of cognitive abilities. Regarding the support, it has been noted that the inclusion of an interactive support, through different kinds of feedback (e.g., are you sure about the relationship between concept A and B?) facilitates, in elementary students, the collaborative concept mapping on contents of knowledge domain of natural sciences (Hwang, $\mathrm{Wu}, \& \mathrm{Ke}, 2011$ ). This kind of support does not only fosters learning performance with concept maps created with CmapTools software, but also increases students' positive attitudes toward learning and interest in the review process of their own learning process (Hwang et al., 2011).

Nevertheless, in his research with higher education students, Gao (2007) has found that aid - such as the availability of keywords, prior individual preparation, or the combination of both - did not impacted significantly on the performance achieved by students grouped in pairs in a problem-solving task with the use of concept mapping nor on their attitudes towards learning and collaboration. This study used book chapters and problem-solving task addressing a topic related to educational psychology as learning materials. Likewise, the views of students referred to positive aspects, but also to negative aspects about the support that was provided. Regarding the availability of key concepts, participants noted, first, that it was useful to generate and share a number of related concepts and to proceed in a more efficient way in the collaborative task. But on the other hand, some students also felt that the support may have slowed the mapping task - probably because it forced them to reflect about their disagreements, argumentations, and negotiations- and some students felt constrained at generating their own ideas.

This paper aims to provide empirical evidence about the effects that an aid would generate, such as providing a list of key concepts, in a task of collaborative construction of concept maps from the review of multimedia material. The aid consists on a disorganized list of 30 key concepts that appear in the multimedia material to be used. This support is similar to the "Concept Suggestions" aid that the CmapTools software shows (Cañas et al., 2004) and some scaffolding used in previous research such as Hauser et al. (2006). At the experimental condition such aid was included, whereas at control condition no support was given. To build the concept map, students must identify, on their own, the main concepts and establish their links from the information presented in the multimedia. To test the cognitive aid of the keyword list, the influence at the performance reached by the teams in a collaborative concept mapping task and the assessment of the levels of collaboration achieved by students was considered. It was expected that the key concepts list would operate as a useful scaffold to: a) identify and retain the central ideas presented in the multimedia material; b) promote the integration of new information with previous knowledge; and, c) detect and repair flaws in their comprehension. Following the cognitive load theory, it would enable to reduce extrinsic cognitive load by releasing mental resources to activate processes that are linked as much with an elaborative process and a metacognitive one, as well as the planning, management and supervision of the collaborative actions, that is with the co-regulatory process (Manlove, Lazonder \& De Jong, 2009).

Therefore, the next hypothesis were raised: a) Cognitive aid favors the building of concept maps of a greater quality and complexity, taking into account indications about their topological features, and above all, the semantic ones; such as hierarchical structure, propositions correction and integration (concepts and links) (Hypothesis 1); b) Cognitive aid promotes higher collaboration levels on the teams that received support compared to those groups that worked without them (Hypothesis 2). 


\section{Method}

\subsection{Participants and design}

The study was held with the participation of 57 Mexican university students enrolled in a psychology of communication course at the UASLP Autonomus University of San Luis Potosí (Mexico), 38 women and 19 men, grouped into 19 triads. The mean of the variable age of the participants was $19.30(\mathrm{SD}=1.83)$. Each triad was assigned to one of two conditions: with support from the list of key concepts $(n=10$ triads, with 30 students, 23 women and 7 men) and without support ( $n=9$ triads, with a total of 27 participants, 15 women and 12 men). Nearly all students had an average socioeconomic status. There was control so that there would be no previous significant differences between the groups regarding reading comprehension, regulation strategies of reading comprehension and prior knowledge in the specific domain and in concept mapping. Participants were previously trained in concept mapping in two group sessions (large group) of 20 minutes each. Participation by students was voluntary and as a bonus, they received credits in their subjects.

\subsection{Materials}

The learning material consisted on a multimedia digital document on Interpersonal communication and the Double Bind Theory of Bateson (1985). The multimedia was structured into 5 content blocks that could be journeyed in a nonlinear way, namely: - systems theory - axioms of communication - contributions and Bateson labor camps - bind and paradoxical theory and - necessary conditions for the double bind to appear. In the different blocks, written expository texts were combined in audio, narrated video and podcasts. The multimedia document was prepared with Prezi program. Since the structure of the multimedia was not linear, participants had the power to use and explore it at any order they wanted to.

\subsection{Instruments}

To assess the reading comprehension skills of the students, two tasks were applied. The Multimedia Comprehension Battery (abridged version) of Gernsbacher and Varner (1988), adapted by Díez and Fernández (1997) was administered to assess the reading comprehension level. In this test, students are asked to read a computerized text, "The Most Precious Gift", and after reading it, answer eight multiple-choice questions, each with five response options on the content presented in the text. The selected multimedia test battery controls the presentation time of the text, keeping it constant, and also provides a uniform time ( 20 seconds) to answer each of the assessment items. Each correct question is worth a point to a maximum of eight for the questionnaire in total.

For the assessment of reading comprehension self-regulation strategies, the Scale of Assessment of Self-Regulated Learning from Texts - ARATEX (Solano, Núñez, González-Pienda, Álvarez, González, González-Pumariega, \& Rodríguez, 2005) was used. It has 23 items and the valuation is carried out through a Likert scale with five response options about the frequency with which they carry out the activity described in the item $(1=$ never, $5=$ always $)$. The factorial structure of the scale consist on five interrelated dimensions : cognition strategies (cognitive dimension, with 6 items), motivational strategies (motivational dimension, with 5 items), resource management strategies (resource management dimension or support with 6 items), metacognition strategies (assessment dimension, with 4 items), and context strategies (context dimension, with 2 items). The scale provides information about the real situation of college students in relation to their effectiveness in controlling the process of understanding and learning. For example, "When I finish the text, I check if I understood everything well."

The domain-specific prior knowledge level was examined by means of a questionnaire with 6 multiple-choice questions, each with four response options. For example, one of the items was: 4. Point out the correct idea: According to Watzlawick (1967), communication can be...a) only digital; b) only analogue; c) analogue and digital; d) none of the above. The maximum score that students can get in either set of questions is 6 points.

The quality of the concept maps was assessed according to the scoring system used by Liu (2011), in relation to the proposal of Novak and Gowin (1984). Scores were awarded by: number of relevant concepts (1 point for each significant concept), number of hierarchical levels (5 points for each valid hierarchical level), number of cross-links (10 points for each valid cross-link), and number of examples (1 point for each correct example). Furthermore, an adaptation was introduced into the assessment, as it considered the number of links correctly labeled ( 2 points for each correct link) (Hillbert \& Renkl, 2009; Rafferty \& Fleschner, 1993).

To rate the level of cooperation perceived by participants, the Collaboration Questionnaire developed by Chan \& Chan (2011), was used and developed based on the notion of collaborative knowledge construction described by Scardamalia and Bereiter (2006). This questionnaire consists on 12 items rated on a 5-point Likert scale, according to the collaborative experience that the students had in their respective teams. The different items reflect the 12 principles 
of collaborative learning proposed by Scardamalia (2002) and Scardamalia \& Bereiter (2006), that emphasize collaboration in terms of shared cognitive responsibility and in the advancement of knowledge. The principles are related to: a) Improvable ideas (Principle 1); b) Community knowledge and collective responsibility (Principle 2); c ) High-level complex thinking (synthesis and building of more advanced knowledge) (Principle 3); d) Diversity of ideas (Principle 4); e) Democratizing knowledge (Principle 5); f) Epistemic agency and negotiation of meanings (Principle 6); g) Discourse aimed at the building of knowledge (Principle 7); h) Concurrent assessment (Principle 8); i) Symmetric advancement (Principle 9); j) Constructive uses of the information (Principle 10); k) Authentic problems and real ideas (Principle 11); and 12) Pervasive knowledge building (Principle 12 ). For example: "Our points of view and knowledge increased while working with others", refers to Principle 2 of Community knowledge.

\subsection{Procedure}

The study was carried out in three sessions. On the first two (40 minutes each), students received instructions on concept mapping and the instruments to control pre-test variables were applied. On the first session the hallmarks of the concept map were explained, showing the elaboration techniques; some of its applications and psycho pedagogic principles were also discussed and we addressed the relevance of using this tool in universities (Aguilar Tamayo, 2004). In addition, tests of reading comprehension and control strategies for reading were applied. On the second session, a practice of modeling for concept mapping on contents from everyday life, using pencil and paper was carried out. In this session the prior knowledge questionnaire of the specific domain was administered. On the third one, a 60 minutes collaborative learning session was held. At the beginning, objectives and instructions to perform the task were explained. Subsequently, groups had 40 minutes to develop collaborative concept maps and finally, participants answered the self-assessment questionnaire on collaboration in teams. The students created concept maps with digital pens (Livescribe Smartpen). Thereafter, the concept maps were transferred to CmapTools V. 5 [Computer Application] (Institute for Human and Machine Cognition HIMC, 2009) in order to ease the evaluation.

\section{Results}

A non parametrical analysis was carried out to compare two independent samples, establishing the experimental condition (with and without cognitive aid) as the group variable; and as dependent measurements, the different scores that assess both the quality of the concept map and the collaboration level perceived by students. Due to the impossibility to guarantee a normal distribution and the stability of the variance in variables, the non-parametric Mann-Whitney $\mathrm{U}$ test was used, which is an excellent alternative to the parametric $t$ test.

For data analysis, we have worked with a level of statistical significance of $\mathrm{p}<.05$, and the Statistical Package for Social Science (SPSS) version 15.0 for Windows software was used.

It was proved that both conditions (with and without cognitive aids) were equivalent at the control variables: a) reading comprehension; b) regulation of reading comprehension strategies; and, c) the level of domain-specific prior knowledge .

Quantitative analysis of the results (with the non- parametric Mann-Whitney U test) shows the existence of significant effects of the aid regarding the quality of collaborative maps. At comparing both conditions, no significant differences in the levels of collaboration and participation achieved in the triads were found.

The results obtained in the variable: quality of the collaborative concept maps are presented in Table 1.

On one hand, the condition with the support of list of key concepts fostered conceptual maps of higher quality than the unsupported condition (Mann-Whitney $\mathrm{U}=91.50 ; \mathrm{Z}=-.49 ; \mathrm{p}=.00$ ). As such, these maps were superior in the following aspects: score for number of valid concepts (Mann-Whitney $U=58.50 ; Z=-5.49 ; p=.00$ ), score by number of valid links (Mann-Whitney $U=112.50 ; Z=-4.61 ; p=.00$ ), score for correct hierarchies (Mann-Whitney $U=84.00$; $\mathrm{Z}=-5.37 ; \mathrm{p}=.00)$.

Table 1. Performances of the two conditions in variables related to quality of collaborative concept maps

\begin{tabular}{lcc}
\hline & Condition with aid & Condition witouth aid \\
\hline Concepts & $15.86(4.59)$ & $9.92(1.99)$ \\
Correct links & $17.20(6.63)$ & $9.00(3.88)$ \\
Correct Cross-links & $4.00(6.74)$ & $2.30(4.29)$ \\
Valid hierarchical levels & $23.66(4.34)$ & $16.15(2.93)$ \\
Examples & $23.66(4.34)$ & $.00(.00)$ \\
Total & $23.66(4.34)$ & $37.38(9.70)$ \\
\hline
\end{tabular}

Notes. Values in columns represent means. Standard deviations are shown in brackets. 
Furthermore, in relation to cross-links and examples, although the groups with an aid condition scored higher than the groups in the control condition, differences were not significant (Mann-Whitney $U=354.00 ; Z=-.765 ; p=.44$ for cross-links, and for examples: Mann-Whitney $U=351.00 ; Z=-1.64: p=.10$ ).

Regarding the levels of collaboration, Table 2 shows the means and standard deviations corresponding to each of the items and the total score obtained by the two conditions in the questionnaire to assess levels of collaboration.

Table 2. Levels of collaboration in the two conditions

\begin{tabular}{lcc}
\hline & Condition with aid & Condition witouth aid \\
\hline Improvable ideas & $4.31(.66)$ & $4.09(.81)$ \\
Community knowledge and collective & $4.48(.57)$ & $4.40(.79)$ \\
responsibility & & \\
High-level complex thinking & $4.20(.81)$ & $4.36(.72)$ \\
Diversity of ideas & $4.34(.66)$ & $4.40(.66)$ \\
Democratizing knowledge & $3.89(.77)$ & $4.00(.69)$ \\
Epistemic agency and negotiation of & $4.00(.70)$ & $4.09(.68)$ \\
meanings & & \\
Discourse aimed at the building of & $4.17(.75)$ & $4.27(.82)$ \\
knowledge & $4.27(.59)$ & $4.40(.66)$ \\
Concurrent assessment & $4.41(.68)$ & $4.50(.67)$ \\
Symmetric advancement & $3.89(1.31)$ & $3.63(1.09)$ \\
Constructive uses of the information & $4.13(.63)$ & $4.36(.58)$ \\
Authentic problems and real ideas & $4.20(.67)$ & $4.31(.83)$ \\
Pervasive knowledge building & $4.19(.37)$ & $4.23(.38)$ \\
Total &
\end{tabular}

Notes. Values in columns represent means. Standard deviations are shown in brackets.

No significant differences in the assessment of levels of cooperation achieved in the groups of both conditions in the total score of the questionnaire (Mann-Whitney $U=301.00 ; Z=-.601 ; p=.54$ ) were found. Likewise, in none of the 12 items that refer to the principles for collaboration no significant differences were found when comparing groups with and without aid.

\section{Discussion}

The collaborative multimedia learning requires from students a range of cognitive, metacognitive and affective motivational demands. Such requirements are related to: a) the information processing presented in various representational formats- in a nonlinear and interactive way- (Mayer, 2005; Schnotz, 2002); and, b) complex mental processes to plan, manage and monitor collaborative actions, that is, to co-regulate such activity (Bodemer \& Scholvien, 2008 ). It has been said that Collaborative Concept mapping can function as an appropriate strategy to foster higher levels of learning in educational contexts. However, this is not an easy task, especially for novice mappers or for students with low prior knowledge levels or little experience in collaborative activities (Gao, 2007). So, some sort of scaffolding is needed that will allow students to meet the requirements of said task. Aids, such as making keywords and predefined links available to students, or providing support and different kinds of feedback have been proposed and examined by scientific research on collaborative concept mapping to facilitate the targeting of core contents of a given topic and promote collaborative processes (Chiu et al., 2000).

In this study we tested a scaffold that consisted in providing students with a disorganized list of the main concepts that appear in a multimedia material on a topic of interpersonal communication, while performing a task of collaborative concept mapping. This support is similar to the CmapTools software "Concept Suggestions" (Cañas et al, 2004) and to some scaffolding that has been used in previous research, both in individual (Hauser et al, 2006) and collaborative tasks with concept mapping (Gao, 2007). However, in this study, in contrast to the previously mentioned ones, cognitive aid was used in learning tasks with multimedia texts.

In this study we observed a positive effect of using an aid in a number of quality indicators of the maps, unlike previous research that has tested a similar aid - for example, Hauser et al. (2006) on individual tasks and Gao (2007) on collaborative tasks, without significantly affecting the learning performance of students. 
First, the results of the empirical study show that, in effect, the groups pertaining to the experimental condition who have used such support created concept maps of a higher level of quality than the groups belonging to the unaided condition. This was reflected not only in the total scores awarded to the concept maps, but also in certain specific measures, based on the number of concepts, semantically correct links and to levels and relevance of conceptual hierarchies established in the maps.

When students are involved in a task of collaborative concept mapping, one of the first actions deployed -alongside the multimedia processing involved in the review of the learning material - has to do with the identification and selection of keywords and tags that will serve as links to construct propositions that will shape the conceptual map. Along with this, they use a series of processes to hierarchically organize the propositions to build an overall idea of the text. They are also required to activate their prior knowledge schemes in order to establish new inferential link. In a collaborative task, additionally, students must share and negotiate each of these actions, reviewing and evaluating the product being constructed and how they collaborate.

In this sense, as a possible explanation onthe effects of the scaffold proposed in the quality of concept maps, it could be discussed that making a list available would help, to begin with, to foster the most basic levels of activity involved in a micro-structural type of processing, that is, in the processing related with reduction and construction functions referred by Hilbert and Renkl (2009). This would be reflected in the higher scores related to the number of main concepts and semantically correct links. Moreover, the aid would free cognitive resources -that is to say, it would increase the relevant cognitive load - engaging them in higher levels of processing associated, especially with rebuilding the macrostructure of the multimedia text (Amadieu \& Salmeron, in press). Hence, the groups who worked with the cognitive aid obtained higher scores in relation to the hierarchical organization of the concept maps they developed. However, the aid would be insufficient to enable teams to establish inferential elaborations correctly and creatively, connecting central concepts with their prior knowledge or with other key concepts, whose relationship is not very obvious in the topic addressed. Such as would be suggested by the absence of significant differences in this score.

It is worth considering, first, that in his study Gao (2007) enclosed the use of collaborative concept mapping in higher learning structure based on problem solving, which involves more complexity in the cognitive, metacognitive and motivational demands. Also, for performance assessment he took into account the final results of problem-based learning and not the quality of the concept maps, as in our study. In an effort to reconcile both results, it might be possible to think that the availability of key concepts for collaborative concept mapping tasks could be effective only when it is used in an activity directed to the comprehension and information acquisition, not so for a more complex learning activity, such as problem solving related tasks.

On the other hand, the results obtained differed to those drawn in Hauser's research (Hauser et al., 2006). It is important to note that in such study the concept mapping task was performed individually. In our study, dealing with collaborative concept mapping, it should be borne in mind that students benefited from double scaffolding: from the support given by the list of keywords, added to the support given by the participations, exchanges and negotiations of their team peers. Scientific research has shown that in collaborative tasks it is feasible that learners are prompted to externalize their ideas, which would contribute to the awareness of potential biases and deficits in self- understanding, and at the same time, would lead to a reorganization or to a more elaborate construction of their knowledge from the negotiation exchanges with peers (van Boxtel et al., 2000; van der Linden, Erkens, Schmidt, \& Renshaw, 2000). From a Vygotskian view, following Cripps Clark (in press), it could be argued that collaboration would allow the creation of multiple, overlapping zones of proximal development, in which students can scaffold each other at developing conceptual maps.

However, to prove these expectations it would be necessary to have studies that not only compare single concept mapping against collaborative concept mapping, but also to examine the type and quality of interactions and the collaborative structure in which the use of collaborative concept mapping is delimited.

In second place, contrary to our expectations, providing key concepts as support in the task of collaborative mapping has not had positive effects on the perceived levels of collaborations that the students perceived. This result is consistent with what was observed by Gao (2007) in his study of education students. Following, (Summers \& Volet, 2010; Volet, Summers, \& Thurman, 2009) in a collaborative task two groups of processes can be deployed: one, implied in the processing of high cognitive and metacognitive levels, specifically, the implementation of the learning task, and, another, addressed to the shared or social regulation of the activity, that is, the co - regulation of group interaction. The first type of processes would appear in exchanges related to the regulation of the activity according to the product to be constructed, for example, asking questions providing explanations and clarifications, that is, it would have to do with the control of the task according to Saab (2012), while in the second group, interactions would refer to 
the organization and management of the group, for example, agreeing on participation shifts and generat agreements in the negotiation, that is, deal with the group regulation. Both, the regulation of the task in terms of performance and the specific regulation of the way to collaborate, are key to the effectiveness of collaborative learning (Saab, 2012). In this regard, taking into account the results obtained in our study, one could infer that the aid of the list of keywords would not specifically affect the co-regulation. In this case other methods of support are required, such as providing learners with instructions on how to collaborate (Saab, van Joolingen, \& van Hout-Wolters, 2007; 2012).

Along with this, it should also be borne in mind that in our study the assessment of levels of collaboration perceived by students in their teams reached quite high scores for both conditions (greater than 4 out of a maximum of 5). It would be advisable to complement this analysis with other instruments or with qualitative method procedures to collect the exchanges that on-line mode students displayed, that is, during the same time collaborative work is being developed.

On the other hand, high scores on the perceived level of collaboration could be thought as a byproduct of using concept maps, in this case in future research it could be useful to compare this strategy with other instructional supports.

\section{Limitations and future directions}

Regarding study limitations, it is important to consider the characteristics of the college students who participated in the study. These are students with low prior knowledge and reading control, which are novice mappers and have little experience in collaborative work. In future research it would be interesting to also offer a design to examine the effects of support in groups involving students with higher levels in the variables that were monitored in this study (prior knowledge, reading control, experience in mapping tasks) .

Moreover, to examine the levels of cooperation, the applied instrument involved a short questionnaire in Likert scale (Chan \& Chan, 2011). In following studies it would be appropriate to triangulate said instrument with qualitative procedures, in addition to online registration of what happens in the collaborative task to understand the dynamics of interactions and processes of both the specific learning task control and collaboration or co -regulation control.

It should also be considered that in this study, work has been over a topic related to human sciences (interpersonal communication). It might be interesting to replicate the effect of cognitive aid in learning tasks that use multimedia materials at topics related to other knowledge domains, such as natural sciences. A great part of the studies with collaborative concept maps cover topics on this certain field. Besides, knowledge domain could influence on the effect of the examined cognitive aid (Nesbitt \& Adesope, 2006).

\section{Conclusions}

This study found a positive impact of a cognitive aid that consisted in providing groups with a list of key concepts in a collaborative concept mapping task, in which multimedia material was used.

It may probably be needed to escort this aid with another kind of support, specifically directed to foster processes related to co-regulation of the interaction and exchanges at collaborative learning scenarios that use concept maps.

\section{Acknowledgements}

The present research was supported by funding from Programa de Mejoramiento del Profesorado de la Secretaría de Educación Pública de México (PROMEP/103.5/12/3953), awarded to the first author. The authors also acknowledge the assistance provided by Lillian Harris A. for the translation of this article and Andrea Robles for revising the English grammar. The authors also appreciate the thoughtful revisions and helpful suggestions made by the associate editor and two anonymous reviewers, which clearly contributed to substantially improving the paper.

\section{References}

Aguilar Tamayo, M. F. (2004). El Mapa Conceptual: Un texto a interpretar. In A. J. Cañas, J. D. Novak y F. M. González (Eds.), Concept Maps: Theory, Methodology, Technology. Proceedings of the First International Conference on Concept Mapping (Vol. I, pp. 31-38). Navarra, España: Universidad Pública de Navarra.

Amadieu, F. y Salmerón, L. (in press). Concept maps for comprehension and navigation of hypertexts In J. D. Ifenthaler \& R. Hanewald (Eds.), Digital Knowledge Maps in Education: Technology-Enhanced Support for Teachers and Learners (pp. 41-59). New York: Springer.

Basque, J., \& Lavoie, M.-C. (2006). Collaborative concept mapping in education: major research trends. In A. J. Cañas, J. D. Novak (Eds), Concept Maps: Theory, Methodology, Technology. Proceeding of the Second International Conference on Concept Mapping (Vol. 1, pp. 79-86). San Jose, Costa Rica: Universidad de Costa Rica.

Bateson, G. (1985). Pasos hacia una ecología de la mente. Buenos Aires: Carlos Lohlé. 
Bodemer, D., \& Scholvien, A. (2008). Support for collaborative multimedia learning: considering the individual and the group. In T.-W. Chan et al. (Eds.), Proceedings ICCE 2008. The 16th International Conference on Computers in Education (pp. 245-252). Taipei, Taiwan: Asia-Pacific Society for Computers in Education.

Cañas, A. J., \& Novak, J. D. (2005). A concept map-centered learning environment. Paper presented at the Symposium at the 11th Biennial Conference of the European Association for Research in Learning and Instruction (EARLI), Cyprus.

Cañas, A. J., Hill, G., Carff, R., Suri, N., Lott, J., Eskridge, T., et al. (2004)._CmapTools: A knowledge modeling and sharing environment. In A. J. Cañas, J. D. Novak, \& F. M. González (Eds.), Concept maps: Theory, methodology, technology. Proceedings of the first international conference on concept mapping (Vol. I, pp. 125-133). Pamplona, Spain: Universidad Pública de Navarra.

Carter, C. W. (1998). A case study of meaningful learning in a collaborative concept mapping strategy as a preparation for a college biology laboratory. Unpublished doctoral dissertation, Georgia State University, Atlanta.

Chan, C., \& Chan, Y. (2011). Students' views of collaboration and online participation in Knowledge Forum. Computers and Education, 57, 1445-1457. http://dx.doi.org/10.1016/j.compedu.2010.09.003

Chang, K. E., Sung, Y.-T., \& Chen, S. F. (2001). Learning through computer based concept mapping with scaffolding aid. Journal of Computer Assisted Learning, 17(1), 21-33. http://dx.doi.org/10.1111/j.1365-2729.2001.00156

Chang, K.-E., Sung, Y.-T., \& Chen, S.-F. (2002). The effect of concept mapping to enhance text comprehension and summarization. The Journal of Experimental Education, 71(1), 5 - 23. http://dx.doi.org/10.1080/00220970209 602054

Chiu, C.-H., Huang, C.-C., \& Chang, W.-T. (2000). The evaluation and influence of interaction in network supported collaborative concept mapping. Computers and Education, 34, 17-25. http://dx.doi.org/10.1016/S0360-1315(99) 00025-1

Chularut, P., \& DeBacker, T. K. (2003). The influence of concept mapping on achievement, self-regulation, and self-efficacy in students of English as a second language. Contemporary Educational Psychology, 29, 248-263. http://dx.doi.org/10.1016/j.cedpsych.2003.09.001

Cripps Clark, J. (in press). Towards a Cultural Historical Theory of Knowledge Mapping: Collaboration and Activity in the Zone of Proximal Development. In J. D. Ifenthaler \& R. Hanewald (Eds.), Digital Knowledge Maps in Education: Technology-Enhanced Support for Teachers and Learners (pp. 161-174). New York: Springer.

Díez, E., \& Fernández, A. (1997). Batería multimedia de comprensión (versión abreviada). Universidad de Salamanca.

Dillenbourg, P. (1999). What do you mean by collaborative learning? In P. Dillenbourg (Ed.), Collaborative-learning: Cognitive and computational approaches (pp. 1-19). Oxford: Elsevier.

Gao, H. (2007). The Effects of Key Concepts Availability and Individual Preparation in the form of Proposition Formation in Collaborative Concept Mapping on Learning, Problem Solving, and Learner Attitudes. Electronic Theses, Treatises and Dissertations. Paper 4364. Available from http://diginole.lib.fsu.edu/cgi/viewcontent. cgi? article $=1593 \&$ context $=$ etd

Gao, H., Shen, E., Losh, S., \& Turner, J. (2007). A review of studies on collaborative concept mapping: What have we learned about the technique and what is next? Journal of Interactive Learning Research 18(4), 479-492.

Gernsbacher, M. A., \& Varner, K. R. (1988). The multimedia comprehension battery. Eugene, OR: University of Oregon, Institute of Cognitive and Decision Sciences.

Haugwitz, M., Nesbit, J., \& Sandmann, A. (2010). Cognitive ability and the instructional efficacy of collaborative concept mapping. Learning and Individual Differences, 20, 536-543. http://dx.doi.org/10.1016/j.lindif. 2010.04.004

Hauser, S., Nückles, M., \& Renkl, A. (2006). Supporting concept mapping for learning from text. In S. A. Barab, K. E. Hay, \& D. T. Hickey (Eds.), Proceedings of the 7th International Conference of the Learning Sciences (pp. 243-249). Mahwah, NJ: Erlbaum.

Hilbert, T. S., \& Renkl, A. (2008). Concept mapping as a follow-up strategy to learning from texts: What characterizes good and poor mappers? Instructional Science, 36, 53-73. http://dx.doi.org/ 10.1007/s11251-007-9022-9

Hilbert, T. S., \& Renkl, A. (2009). Learning how to use a computer-based concept-mapping tool: Self-explaining examples helps. Computers in Human Behavior, 25, 267-274. http://dx.doi.org/10.1016/j.chb.2008.12.006 
Hilbert, T. S., Nuckles, M., \& Matzel, S. (2008). Concept mapping for learning from text: evidence for a worked-out-map-effect. ICLS, 1, 358-365.

Hwang, G. J., Wu P.H., \& Ke, H. R. (2011). An interactive concept map approach to supporting mobile learning activities for natural science courses. Computers \& Education, 57, 2272-2280. http://dx.doi.org/10.1016/ j.compedu.2011.06.011

IHMC. (2009). CmapTools V. 5 [Aplicación Informática].Institute for Human and Machine Cognition. (http://cmap.ihmc.us).

Jonassen, D. H., Lee, C. B., Young, C. C., \& Laffey, J. (2005). The Collaboration principle in Multimedia Learning. In R. Mayer (Ed.), Cambridge Handbook of multimedia learning (pp. 247-270). Cambridge: Cambridge University Press. http://dx.doi.org/10.1017/CBO9780511816819.017

Kinchin, I. M., De-Leij, F. A., \& Hay, D. B. (2005). The evolution of a collaborative concept mapping activity for undergraduate microbiology students. Journal of Further and Higher Education, 29(1), 1-14. http://dx.doi.org $10.1080 / 03098770500037655$

Kwon, S. Y., \& Cifuentes, L. (2009). The comparative effect of individually-constructed vs. collaboratively-constructed computer-based concept maps. Computers and Education, 52, 365-375. http://dx.doi.org/10.1016/j.compedu.2008.09.012

Liu, P. (2011). A study on the use of computerized concept mapping to assist ESL learners' writing. Computers \& Education, 57(4), 2548-2558. http://dx.doi.org/10.1016/j.compedu.2011.03.015

Liu, P-L., Chen, Ch-J., \& Chang, Y-J. (2010) Effects of a computer-assisted concept mapping learning strategy on EFL college students' English reading comprehension. Computers and Education, 54(2), 436-445. http://dx.doi.org/10.1016/j.compedu.2009.08.027

Manlove, S., Lazonder, A.W., \& De Jong, T. (2006). Regulative support for collaborative scientific inquiry learning. Journal of Computer Assisted Learning, 22, 87-98. http://dx.doi.org/10.1111/j.1365-2729.2006.00162.x

Mayer, R. E. (2001). Multimedia learning. New York, NY: Cambridge University Press. http://dx.doi.org/10.1017/CBO9781139164603

Mayer, R. E. (2005). Cognitive theory of multimedia learning. In R. E. Mayer (Ed.), The Cambridge handbook of multimedia learning (pp. 31-48). New York, NY: Cambridge University Press. http://dx.doi.org/10.1017/CBO9780511816819.004

Nesbit, J. C., \& Adesope, A. O. (2006). Learning with concept and knowledge maps: A meta-analysis. Review of Educational Research, 76, 413-448.http://dx.doi.org 10.3102/00346543076003413

Novak, J. D., \& Cañas, A. J. (2006). The Theory Underlying Concept Maps and How to Construct Them (Technical Report IHMC CmapTools 2006-I): Institute for Human and Machine Cognition.

Novak, J. D., \& Gowin, D. B. (1984). Learning how to learn. London: Cambridge University. http://dx.doi.org/10.1017/CBO9781139173469

Oliver, K. M. (2009). An investigation of concept mapping to improve the reading comprehension of science texts. Journal of Science Education and Technology, 18(5), 402-414. http://dx.doi.org/10.1007/s10956-009-9157-3

Paas, F., Renkl, A., \& Sweller, J. (2003). Cognitive load theory and instructional design: Recent developments. Educational Psychologist, 38, 1-4. http://dx.doi.org/10.1207/S15326985EP3801_1

Paivio, A. (1986). Mental representations: A dual coding approach . Oxford: Oxford University Press.

Rafferty, C. D., \& Fleschner, L. K. (1993). Concept mapping: A viable alternative to objective and essay exams. Reading, Research, and Instruction, 32, 25-33. http://dx.doi.org/10.1080/19388079309558122

Rouet, J. F., Levonen J. J., \& Biardeau, A. (2001). Multimedia learning: Cognitive and instructional issues. Amsterdam: Pergamon.

Saab, N. (2012). Team regulation, regulation of social activities or co-regulation: Different labels for effective regulation of learning in CSCL. Metacognition and Learning, 7, 1-6. http://dx.doi.org/ 10.1007/s11409-011-9085-5

Saab, N., van Joolingen, W. R., \& van Hout-Wolters, B. (2012). Support of the collaborative inquiry learning process: influence of support on task and team regulation. Metacognition and Learning, 7, 7-23. 
http://dx.doi.org/10.1007/s11409-011-9068-6.

Saab, N., van Joolingen, W. R., \& van Hout-Wolters, B. H. A. M. (2007). Supporting communication in a collaborative discovery learning environment: The effect of instruction. Instructional Science, 35, 73-98. http://dx.doi.org/10.1007/s11251-006-9003-4

Salomon, G. (1995). Distribuited cognitions: Psychological and educational considerations. Cambridge, UK.: Cambridge, University Press.

Scardamalia, M. (2002). Collective Cognitive Responsibility for the Advancement of Knowledge. In B. Smith (Ed.), Liberal Education in a Knowledge Society, pp. 67-98. Chicago: Open Court.

Scardamalia, M., \& Bereiter, C. (2006). Knowledge building: theory, pedagogy, and technology. In R. K. Sawyer (Ed.), The Cambridge handbook of the learning sciences (pp. 97-119). New York: Cambridge University Press.

Schnotz, W. (2002). Towards an integrated view of learning from text and visual displays. Educational Psychology Review, 14 (2), 101-120. http://dx.doi.org/1040- 726X/02/0300-0101/0.

Solano, P., Núñez, J. C., González - Pienda, J. A., Álvarez, L., González, P., González - Pumariega, S., \& Rodríguez, S. (2005). Análisis de la fiabilidad y validez de la escala ARATEX. In Actas do VIII Congresso Galaico-Portuguès de Psicopedagogía (pp. 647-658). Braga: Universidade do Minho.

Stoyanova, N., \& Kommers, P. (2002). Concept mapping as medium of shared cognition in computer-supported collaborative problem solving. Journal of Interactive Learning Research, 13(1-2), 111-133.

Summers, M., \& Volet, S. (2010). Group work does not necessarily equal collaborative learning: evidence from observations and self-reports. European Journal of Psychology Educational, 25, 473-492. http://dx.doi.org/ 10.1007/s10212-010-0026-5

Sweller, J., van Merrienboer, J. J. G., \& Paas, F. G. W. C. (1998). Cognitive architecture and instructional design. Educational Psychology Review, 10 (3), 251-296. http://dx.doi.org/10.1023/A:1022193728205

van Boxtel, C., van der Linden, J. L., \& Kanselaar, G. (1997). Collaborative construction of conceptual understanding: interaction processes and learning outcomes emerging from a concept mapping and poster task. Journal of Interactive Learning Research, 8 (3-4), 341-361.

van Boxtel, C., van der Linden, J. L., \& Kanselaar, G. (2000). Collaborative learning tasks and the elaboration of conceptual knowledge. Learning and Instruction 10, 311-330. http://dx.doi.org/10.1016/S09594752(00)00002-5

van Boxtel, C., van der Linden, J. L., Roelofs, E., \& Erkens, G. (2002). Collaborative concept mapping: Provoking and supporting meaningful discourse. Theory into Practice, 41(1), 40-46. http://dx.doi.org/10.1207/s15430421tip4101_7

van der Linden, J., Erkens, G., Schmidt, H., \& Renshaw, P. (2000). Collaborative Learning. In P. R. J. Simons, J. van der Linden, \& T. Duffy (Eds.), New learning (pp. 37-57). Dordrecht: Kluwer Academic Publishers.

Volet, S., Summers, M., \& Thurman, J. (2009). High-level co-regulation in collaborative learning: how does it emerge and how is it sustained? Learning and Instruction, 19, 128-143. http://dx.doi.org/10.1016/j. learninstruc.2008.03.001

Vygotsky, L. (1978). Mind in Society: the Development of Higher Psychological Process. Cambridge, MA: Harvard University Press.

Weinstein, C. E. y Mayer, R. E. (1986). The teaching of learning strategies. In C. M. Wittrock (Ed.), Handbook of research in teaching (pp. 315-327). New York: Macmillan Publishing Company.

Wood, D. J., Bruner, J. S, \& Ross, G. (1976). The role of tutoring in problem solving. Journal of Child Psychology and Psychiatry, 17, 89-100. http://dx.doi.org/10.1111/j.1469-7610.1976.tb00381.x 